\title{
Inhibition of Glycogen Synthase Kinase $3 \beta$ Blocks Mesomesenchymal Transition and Attenuates Streptococcus pneumonia-Mediated Pleural Injury in Mice
}

\author{
Jake Boren, Grant Shryock, Alexis Fergis, Ann Jeffers, Shuzi Owens, Wenyi Qin, Kathleen B. Koenig, Yoshikazu Tsukasaki,
} Satoshi Komatsu, Mitsuo Ikebe, Steven Idell, and Torry A. Tucker

From the Department of Cellular and Molecular Biology, The University of Texas Health Science Center at Tyler, Tyler, Texas

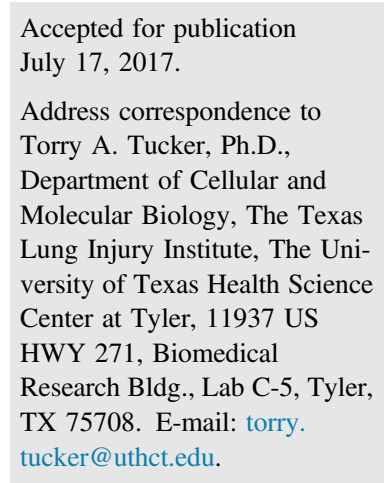

\begin{abstract}
Pleural loculation affects about 30,000 patients annually in the United States and in severe cases can resolve with restrictive lung disease and pleural fibrosis. Pleural mesothelial cells contribute to pleural rind formation by undergoing mesothelial mesenchymal transition (MesoMT), whereby they acquire a profibrotic phenotype characterized by increased expression of $\alpha$-smooth muscle actin and collagen 1. Components of the fibrinolytic pathway (urokinase plasminogen activator and plasmin) are elaborated in pleural injury and strongly induce MesoMT in vitro. These same stimuli enhance glycogen synthase kinase (GSK)-3 $\beta$ activity through increased phosphorylation of Tyr-216 in pleural mesothelial cells and GSK-3 $\beta$ mobilization from the cytoplasm to the nucleus. GSK-3 $\beta$ down-regulation blocked induction of MesoMT. Likewise, GSK-3 $\beta$ inhibitor 9ING41 blocked induction of MesoMT and reversed established MesoMT. Similar results were demonstrated in a mouse model of Streptococcus pneumoniae-induced empyema. Intraperitoneal administration of 9ING41, after the induction of pleural injury, attenuated injury progression and improved lung function (lung volume and compliance; $P<0.05$ compared with untreated and vehicle controls). MesoMT marker $\alpha$-smooth muscle actin was reduced in 9ING41-treated mice. Pleural thickening was also notably reduced in 9ING41-treated mice $(P<0.05)$. Collectively, these studies identify GSK-3 $\beta$ as a newly identified target for amelioration of empyema-related pleural fibrosis and provide a strong rationale for further investigation of GSK-3 $\beta$ signaling in the control of MesoMT and pleural injury. (Am J Pathol 2017, 187: 2461-2472; http://dx.doi.org/10.1016/ j.ajpath.2017.07.007)
\end{abstract}

The most common causes of pleural fibrosis (PF) are pneumonia with complicated parapneumonic effusion (CPE) or empyema, tuberculosis and asbestos-related pleural disease, collagen vascular diseases, and coronary artery bypass graft surgery. ${ }^{1-4}$ Related to pleural infections, the incidence of CPEs is increasing and is associated with increased deaths, especially in patients with comorbidities, including loculation and $\mathrm{PF} .{ }^{4}$ Current surgical treatment for $\mathrm{CPE}$ /empyema is invasive, and alternative treatment with intrapleural fibrinolysins with or without DNase is empirical, not approved by the US Food and Drug Administration or other regulatory agencies, and is associated with variable outcomes in adults. ${ }^{5-7}$

Pleural thickening is clearly related to poor outcomes of CPE/empyema and their treatment, which is designed to facilitate pleural drainage and to limit organization of loculated, pleural fluids that are difficult to drain and may predispose to clinically important $\mathrm{PF}^{8,9}$ Myofibroblasts express increased levels of $\alpha$-smooth muscle actin ( $\alpha$-SMA), migrate into the pleural, and begin proliferating early pleural injury. ${ }^{10-12}$ These cells promote the accumulation of matrix proteins, including collagen 1 (Col-1), that contribute to the formation of the pleural rind and subsequent lung restriction. ${ }^{13}$ The source of these myofibroblasts is likely multifactorial. However, recent studies suggest that

Supported by NIH grant HL115466 (T.A.T.), Seed grant funding from the University of Texas Health Science Center at Tyler (T.A.T.), and The Texas Lung Injury Institute (T.A.T.).

Disclosures: 9ING41 was gifted by Actuate Therapeutics. 
mesomesenchymal transition (MesoMT) of residential pleural mesenchymal cells (PMCs) contributes to the expansion of subpleural myofibroblasts that characterize virtually all forms of pleural injury that progress to PF. ${ }^{10-12,14}$ Further, urokinase plasminogen activator (uPA) and plasmin, mediators that are locally induced in virtually all forms of pleural injury, induce MesoMT. ${ }^{10}$ Unfortunately, there is currently no reliably effective pharmacotherapy to prevent severe PF and to restrict lung disease associated with fibrothorax, particularly in adults. These considerations justify the search for new targets and identification of more effective interventions for PF. ${ }^{15}$

Glycogen synthase kinase (GSK) is a Ser/Thr kinase with two isoforms $(\alpha$ and $\beta) .{ }^{16,17}$ GSK-3 $\beta$ is a constitutively active enzyme; phosphorylation of Tyr-216 residue ( $\mathrm{p}$ $\mathrm{GSK}_{\mathrm{T}}$ ) potentiates its kinase activity. ${ }^{18,19}$ GSK-3 $\beta$ is inactivated by phosphorylation of Ser-9, which acts as a pseudosubstrate and competitively inhibits the kinase's active site. ${ }^{17,19}$ This type of inhibition, however, can be reversed by increasing amounts of primed GSK-3 $\beta$ substrate. ${ }^{20}$ Further, Ser-9 phosphorylation has no impact on GSK$3 \beta-$ mediated phosphorylation of unprimed substrates. The localization of GSK-3 $\beta$ also plays a role in its activity, because GSK-3 $\beta$ localized to the nucleus is reported to be more active than cytosolic pools of GSK-3 $\beta .^{21-23}$ Although first identified as a regulator of glycogen synthase, recent studies have found that GSK-3 $\beta$ can regulate the function of a diverse list of targets, including transcription factors. ${ }^{22,24}$ GSK- $3 \beta$ also regulates a number of signaling pathways that consequently affect the transcriptional activity of numerous inflammatory mediators. ${ }^{18,24-27}$ In some cases inhibition of GSK-3 $\beta$ can drive epithelial-to-mesenchymal transition and can increase the expression of mesenchymal markers, ${ }^{28,29}$ whereas others reported that GSK-3 $\beta$ inhibition blocks fibroblast activation, thus reducing injury in acute injury models. ${ }^{30,31}$ The novel GSK-3 $\beta$ inhibitor, 9ING41, inhibited glycogen synthase phosphorylation and induced apoptosis in cells with aggressive tumor phenotypes at a fivefold lower concentration than other GSK-3 $\beta$ inhibitors. ${ }^{32}$ Further, 9ING41 treatment attenuated tumor progression. $^{32}$

The role of GSK-3 $\beta$ in pleural injury remains unclear and is, to our knowledge, previously unexplored. In this study, the expression of GSK- $3 \beta$ in PMCs was documented, and then the role of GSK-3 $\beta$ signaling was investigated in the induction and progression of MesoMT. In dedicated interventional studies, the contribution of active GSK-3 $\beta$ was evaluated in the progression of pleural injury and PF in Streptococcus pneumoniae-mediated empyema in mice.

\section{Materials and Methods}

\section{S. pneumoniae-Mediated Model of Pleural Injury}

All experiments involving animals were approved by the Institutional Animal Care and Use Committee at the
University of Texas Health Science Center at Tyler. Pleural infections were initiated as previously described. ${ }^{33}$ Briefly, C57BL/6 mice (10 to 12 weeks of age, approximately $20 \mathrm{~g}$; The Jackson Laboratory, Bar Harbor, ME) were first lightly anesthetized with isoflurane. Intrapleural inoculations $\left(1.8 \times 10^{8} \mathrm{cfu}\right.$, resuspended in $0.9 \%$ saline $)$ of $S$, pneumoniae (D39; National Collection of Type Cultures, Salisbury, UK) were delivered by $150-\mu \mathrm{L}$ intrapleural injection. The control group received normal saline under the same conditions. Antibiotic treatment (enrofloxacin, $15 \mathrm{mg} / \mathrm{kg}$ ) was initiated 18 hours after infection and administered daily by subcutaneous injection for 4 days. Infected mice were monitored daily to record body weight, dehydration status, activity, and behavior. If dehydration was detected, mice were subcutaneously injected with 200 to $500 \mu \mathrm{L}$ of warmed $0.9 \%$ saline, as needed. Moribund animals or those that appeared in distress were euthanized with Euthasol. For GSK-3 $\beta$ inhibitor studies, treatment with $30 \mathrm{mg} / \mathrm{kg}$ GSK-3 $\beta$ inhibitor (9ING41, a generous gift from Actuate Therapeutics, Fort Worth, TX), or vehicle control, dimethyl sulfoxide, in a volume of $40 \mu \mathrm{L}$ was administered 24 hours after infection and once daily by intraperitoneal injection for 5 days. Additional negative controls included animals that received intrapleural injections of saline. After administration of $S$. pneumoniae, mice were housed on a heating pad to maintain an ambient temperature of $30^{\circ} \mathrm{C}$ throughout the time course of the experiments.

\section{Lung and Pleural Lavage Collection from S. pneumoniae-Infected Mice}

Lung and pleural lavages were immediately performed at the time of death in selected animals using $3 \times 500 \mu \mathrm{L}$ of sterile normal saline, as previously described. ${ }^{10,33}$ Total white cell and differential cell counts were likewise measured in these fluids, as previously reported. ${ }^{33}$

\section{Cultures of Mouse Pleural Fluids}

Pleural lavages of $S$. pneumoniae-infected or control mice that received intrapleural saline were cultured on blood agar plates containing 5\% sheep blood (Remel Blood Agar; Fisher Scientific, Pittsburgh, PA). Neat $(50 \mu \mathrm{L})$ and 1:100 dilutions of the lavages were cultured on blood agar plates and incubated 15 hours at $37^{\circ} \mathrm{C}$. Colonies were then counted to confirm bacterial burden.

\section{Lung Histologic Examination, Immunostaining, Confocal, Bright Field Microscopy, and Morphometry}

De-identified human pleural tissues were obtained from the National Disease Research Interchange from surgical biopsy or autopsy specimens from patients with a clinical diagnosis of nonspecific pleuritis or from patients with histologically near-normal pleural tissues from patients undergoing lung resection for reasons unrelated to pleural disease or who died from causes otherwise unrelated to any pleural pathologic process. Lung histologic examination and 
immunostaining were performed as previously described. ${ }^{10,33,34}$ All tissue sections (human and murine) were first deparaffinized and subjected to antigen retrieval using a citrate buffer at $95^{\circ} \mathrm{C}$ for 20 minutes. Tissue analyses, collagen deposition, and localization were initially assessed by Trichrome staining as previously described. ${ }^{10,34}$ Morphometric analyses of pleural tissue thickness and depth of underlying pneumonitis were performed as previously described. ${ }^{10}$ Immunofluorescence was used to visualize $\alpha$ SMA (MAB1420; R\&D Systems, Minneapolis, MN), GSK$3 \beta$ (12456; Cell Signaling, Danvers, MA), and calretinin (C7479; Sigma-Aldrich, St. Louis, MO) expression in control saline-exposed and $S$. pneumoniae-infected pleuropulmonary sections as previously described. ${ }^{10}$ Confocal microscopy was then used to visualize immunofluorescence and colocalization of the markers. Images were acquired from a field of view at $0.4-\mu \mathrm{m}$ z-axis increments with the LSM 510 Meta confocal system (Carl Zeiss, Thornwood, NY) at $40 \times$ as previously described. ${ }^{10,35}$

\section{Pulmonary Function Testing}

Pulmonary function tests were performed immediately before computed tomographic (CT) imaging and before sacrifice, as previously described. ${ }^{10,33,34}$ Briefly, mice were anesthetized with a ketamine/xylazine mixture. Anesthetized mice were next intubated by inserting a sterile, 20gauge intravenous cannula through the vocal cords into the trachea. Mice were maintained under anesthesia using isoflurane during pulmonary function testing. Measurements were then performed using the flexiVent system (SCIREQ, Tempe, AZ). The snapshot perturbation method was used to determine lung compliance, according to the manufacturer's specifications.

\section{CT Scans and Measurements of Lung Volume}

Chest CT imaging and measurements of lung volumes were performed as previously described. ${ }^{10,33,34}$ Mice anesthetized with ketamine/xylazine were maintained under anesthesia using an isoflurane/oxygen mixture to minimize spontaneous breaths throughout the procedure. Images were obtained using the Explore Locus Micro-CT Scanner (GE Healthcare, Waukesha, WI). CT scans were performed at a resolution of $93 \mu \mathrm{m}$. Microview software version 2.2 ( $h t t p: / /$ microview.sourceforge.net) $)^{33}$ was used to analyze lung volumes and to render three-dimensional images. Lung volumes were calculated from renditions collected at full inspiration.

\section{PMC Culture and Treatment}

Permission to collect and use human (H)PMCs was granted through an exempt protocol approved by the Institutional Human Subjects Review Board of the University of Texas Health Science Center at Tyler. HPMCs were isolated from pleural fluids collected from patients with congestive heart failure or that were pleural effusions after coronary bypass as previously described. ${ }^{36}$ These cells were maintained in LHC-8 culture media (Life Technologies, Carlsbad CA) containing 3\% fetal bovine serum (Life Technologies), 2\% antibiotic-antimycotic (Life Technologies), and GlutaMAX (Life Technologies) as previously reported. ${ }^{10,35-37}$ Murine (M)PMCs were isolated by trypsin wash and cultured. ${ }^{10}$ All cells were cultured in a humidified incubator at $37^{\circ} \mathrm{C}$ in $5 \%$ $\mathrm{CO}_{2} / 95 \%$ air. Cells were passaged a maximum of five times before discontinuing use. Before use in experiments, all HPMC and MPMC cultures were assayed for expression of the mesothelial cell marker calretinin as previously reported. ${ }^{38}$ Only cultures with a greater than $95 \%$ calretinin positivity were used.

Serum-starved PMCs were treated with $5 \mathrm{ng} / \mathrm{mL}$ transforming growth factor (TGF)- $\beta$ (R\&D Systems), $20 \mathrm{nmol} / \mathrm{L}$ uPA (Sekisui, Lexington, MA), and $7 \mathrm{nmol} / \mathrm{L}$ plasmin (Molecular Innovations, Southfield, MI). Cell lysates and conditioned media then underwent Western blot analysis for $\alpha$-SMA (MAB1420; R\&D Systems), Col-1 (1310-08; Southern Biotech, Birmingham, AL), plasminogen activator inhibitor-1 (PAI3C311; Molecular Innovations), total GSK$3 \beta$ (12456; Cell Signaling), phosphorylated Tyr-216-GSK$3 \beta$ (sc-135653; Santa Cruz Biotechnology, Santa Cruz, CA), total SMAD2 and phosphorylated SMAD2 (11958S; Cell Signaling), and $\beta$-actin (A1978; Sigma-Aldrich) as previously described. ${ }^{10,38}$ For real-time quantitative PCR (qPCR) analyses, total RNA was isolated from treated cells and transcribed into cDNA as previously described. ${ }^{33,38}$ GSK- $3 \alpha$, GSK-3 $\beta$, Col-1, and $\alpha$-SMA expressions were then determined by qPCR (Table 1). Glyceraldehyde-3phosphate dehydrogenase was used as the loading control.

\section{siRNA Transfection}

HPMCS were transfected with $200 \mathrm{nmol} / \mathrm{L}$ control siRNA (SIC002; Sigma-Aldrich), GSK-3 $\beta$ siRNA (forward: 5'AAGAAUCGAGAGCUCCAGUAC[dT][dT]-3'), or GSK-3 $\alpha$

Table 1 Primers Used in This Study

\begin{tabular}{|c|c|}
\hline Primer & Sequence \\
\hline \multirow[t]{2}{*}{ GSK-3 $\alpha($ GSK3A) } & F: 5'-CAАTGTCTCCTACАTСTGTTC-3' \\
\hline & R: 5'-TCGATGGATGAGGTGTAATC- $3^{\prime}$ \\
\hline \multirow[t]{2}{*}{ GSK-3ß (GSK3B) } & F: 5'-TGGAATCTGCCATCGGGATA-3' \\
\hline & R: 5'-ATTGGGTTCTCCTCGGACCA-3' \\
\hline \multirow[t]{2}{*}{ Col-1 (COL1A1) } & F: 5'-GAACGCGTGTCATCCCTTGT-3' \\
\hline & R: 5'-GAACGAGGTAGTCTTTCAGCAACA-3' \\
\hline Col-1 (COL1A1) & $\begin{array}{l}\text { Bio-Rad Prime PCR Probe Assay: FAM } \\
\text { Fluororphore, qHsaCEP0050510 }\end{array}$ \\
\hline$\alpha$-SMA (ACTA2) & $\begin{array}{l}\text { Bio-Rad Prime PCR Probe Assay: FAM } \\
\text { Fluororphore, qHsaCIP0028813 }\end{array}$ \\
\hline GAPDH & $\begin{array}{l}\text { Bio-Rad Prime PCR Probe Assay: HEX } \\
\text { Fluororphore, qHsaCEP0041396 }\end{array}$ \\
\hline
\end{tabular}

$\alpha$-SMA, $\alpha$-smooth muscle actin; Col, collagen; F, forward; GSK, glycogen synthase kinase; $R$, reverse. 
siRNA (forward: 5'-CACUCUAGGCCAAGGCCCA-[dT] [dT]-3') using Lipofectamine 3000 (Life Technologies) according to the manufacturer's instructions as previously described. ${ }^{37,38}$

\section{Statistical Analysis}

All statistics were performed using the $U$-test or $t$-test. A $P$ value $<0.05$ was considered significant.

\section{Results}

\section{GSK-3 $\beta$ Expression Increases in the Mesothelium of Patients with Pleuritis}

First, it was determined whether GSK-3 $\beta$ increases in human pleural injury because it was previously shown that myofibroblasts and collagen deposition increased in lung tissues from patients diagnosed with pleuritis compared with normal lung tissue sections. ${ }^{10}$ PMCs undergoing MesoMT contributed to the progression of PF in chemical and infectious disease pleural injury in mice. ${ }^{10,33}$ To assess the expression of GSK-3 $\beta$ in human PF, GSK-3 $\beta$ was examined in the pleural mesothelium (calretinin) of normal human pleural tissues and those of patients with nonspecific pleuritis. Although GSK-3 $\beta$ was ubiquitously expressed throughout the normal lung tissue (Figure 1A), GSK-3 $\beta$ expression was enhanced in the pleural mesothelium of patients with nonspecific pleuritis compared with that expressed within the normal pleural mesothelium. Increased GSK- $3 \beta$ expression colocalized with the increased expression of the MesoMT marker $\alpha$-SMA in nonspecific pleuritis tissues (Figure 1B).

\section{GSK-3 $\beta$ Is Activated in PMCs Undergoing MesoMT}

Because GSK-3 $\beta$ nuclear localization and phosphorylation at Tyr-216 increased its activity, these features were assessed in HPMCs undergoing MesoMT. TGF- $\beta$ and uPA treatments, which potently induce MesoMT in HPMCs, ${ }^{10,14,38}$ were used to assess changes in the distribution of GSK-3 $\beta$ in stimulated cells. GSK-3 $\beta$ nuclear localization was determined by immunofluorescence analyses. GSK-3 $\beta$ expression was primarily cytoplasmic in phosphate-buffered saline-treated control HPMCS. Conversely, TGF- $\beta$ - and uPA-treated cells demonstrated pronounced nuclear localization of GSK-3 $\beta$ (Figure 2A). These findings demonstrated that these mediators induced GSK-3 $\beta$ mobilization to the nucleus.

The level of Tyr-216 phosphorylation in transitioning HPMCs was next determined. As anticipated, TGF- $\beta$, plasmin, and uPA induced $\alpha$-SMA in HPMCs (Figure $2 \mathrm{~B}$ ). The same mediators concurrently enhanced Tyr-216 phosphorylation of GSK-3 $\beta$. TGF- $\beta$ and plasmin enhanced Tyr-216 phosphorylation most strongly. Tyr216-phosphorylated GSK-3 $\beta$ was detectable in phosphatebuffered saline-treated cells. However, the levels were uniformly below those observed for TGF- $\beta$, plasmin, or uPA. Total GSK- $3 \beta$ was relatively unchanged by TGF- $\beta$, plasmin, or uPA. These studies showed that GSK- $3 \beta$ was activated, as indicated by Tyr-216 phosphorylation, in HPMCs undergoing MesoMT.

\section{GSK-3 $\beta$ Is Critical for the Induction of MesoMT}

Because GSK-3 $\beta$ activation was enhanced in transitioning HPMCs, the role of GSK-3 $\beta$ in the induction of MesoMT was further studied. GSK-3 $\beta$ was significantly down-regulated by siRNA transfection $(>70 \% ; P<0.05)$. TGF- $\beta$ treatment comparably induced $\alpha$-SMA and Col-1 expression in untransfected and control siRNA-transfected cells (Figure 3A). Conversely, GSK$3 \beta$-down-regulated cells demonstrated no induction of $\alpha$-SMA or Col- 1 when treated with TGF- $\beta$. Further, baseline $\alpha$-SMA expression was reduced in GSK-3 $\beta$ downregulated cells compared with control cells. In parallel

\section{A \\ Nonspecific Pleuritis}

Normal

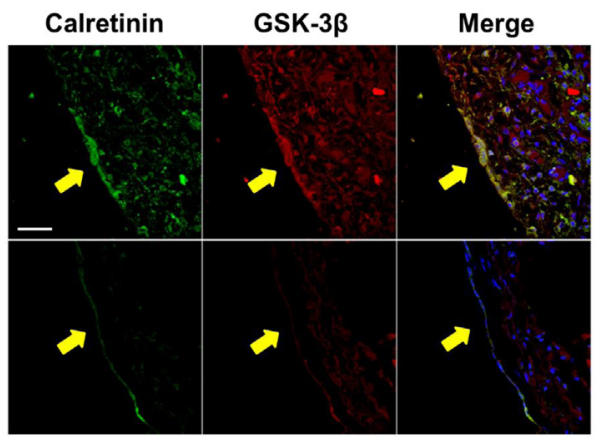

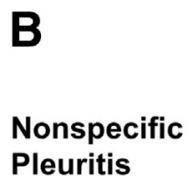

Pleuritis

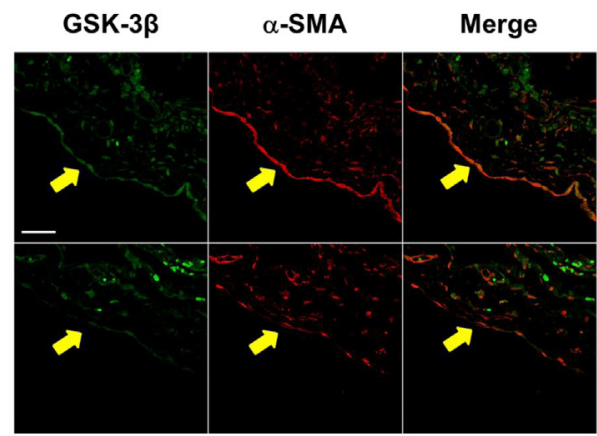

Figure 1 Glycogen synthase kinase (GSK)-3ß expression is enhanced in nonspecific pleuritis. Lung tissue sections from patients diagnosed with nonspecific pleuritis were immunofluorescently labeled. A: GSK-3 $\beta$ expression (red) increases in the pleural mesothelial cells (calretinin; green) of the nonspecific pleuritis tissue. GSK-3 $\beta$ and calretinin colocalization increases in nonspecific pleuritis lung sections (merged; yellow). B: The pleural mesothelium of patients diagnosed

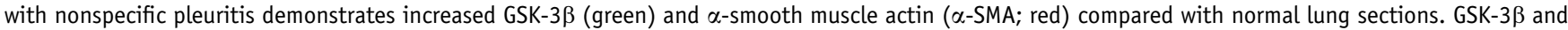
$\alpha$-SMA colocalization (merged; orange) increases in nonspecific pleuritis lung sections. Arrows indicate the mesothelium. $n=30$ fields per slide; $n=3$ to 4 patients per group. Scale bars $=50 \mu \mathrm{m}$. Original magnification, $\times 40$. 
A
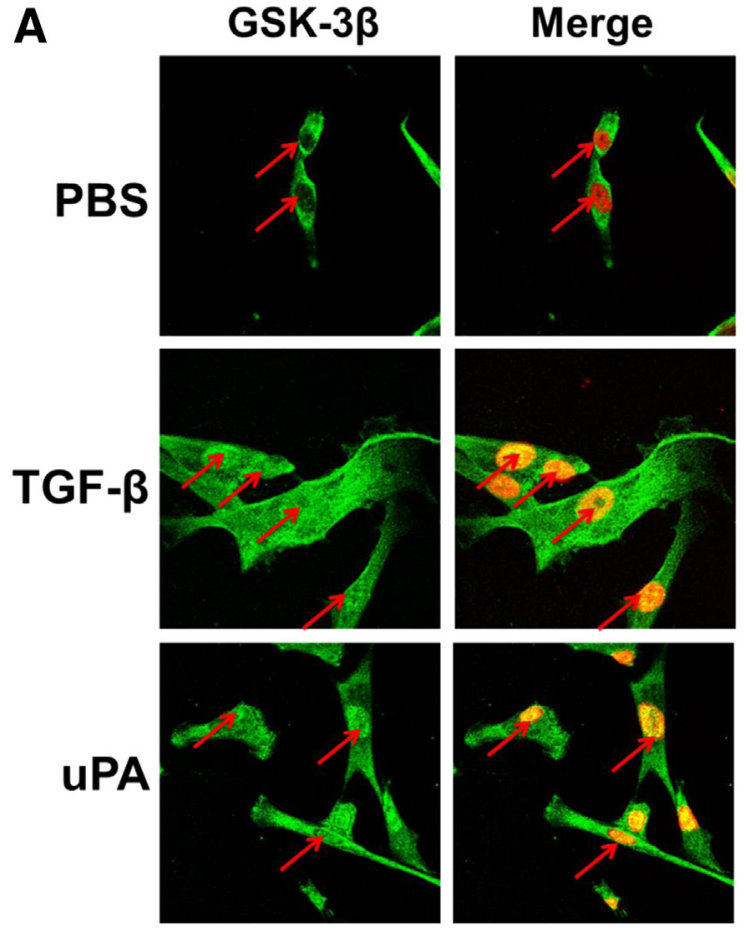

B

PBS TGF- $\beta \quad$ PLN

uPA

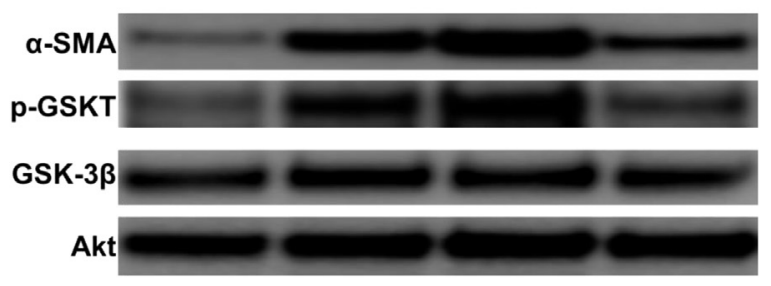

Figure 2 Glycogen synthase kinase (GSK)-3 $\beta$ mobilizes to the nucleus of human primary mesenchymal cells (HPMCs) undergoing mesothelial mesenchymal transition (MesoMT). Serum-starved HPMCs were treated with phosphate-buffered saline (PBS), $5 \mathrm{ng} / \mathrm{mL}$ transforming growth factor (TGF)- $\beta, 7 \mathrm{nmol} / \mathrm{L}$ plasmin (PLN), or $20 \mathrm{nmol} / \mathrm{L}$ urokinase plasminogen activator (UPA) (for 24 and 48 hours). A: PBS-, TGF- $\beta-$, and uPA-treated cells (24 hours) were immunofluorescently labeled for GSK-3 $\beta$ (green) and nuclei (red). Colocalization of GSK-3 $\beta$ and nuclei appear orange. Arrows indicate the location of the nucleus. B: PBS-, TGF- $\beta-$, plasmin-, and UPA-treated HPMCs were lyzed and resolved by SDS-PAGE. Lysates were probed for $\alpha$-smooth muscle actin ( $\alpha$-SMA), total GSK-3 $\beta$, and Tyr216-phosphorylated GSK-3 $\beta$ ( pGSK $_{\mathrm{T}}$ ) by Western blot analysis. Akt was used as loading control. $n=30$ fields per slide $(\mathbf{A}) ; n=3$ slides per treatment (A); $n=2$ independent experiments (B).

qPCR analyses, similar results were observed (Figure 3B), because TGF- $\beta$ failed to induce $\alpha$-SMA and Col- 1 in GSK-3 $\beta$-down-regulated HPMCs. Because GSK-3 has two isoforms ( $\alpha$ and $\beta$ ), the impact of GSK-3 $\alpha$ was studied on the progression of MesoMT. HPMCs with down-regulated GSK-3 $\alpha$ expression (>80\%) demonstrated comparable levels of TGF- $\beta$-mediated induction of $\alpha$-SMA and Col-1 compared with untransfected and control siRNAtransfected cells (Figure 3C). These data showed that the GSK-3 $\beta$ isoform, rather than GSK3 $\alpha$, was involved in the induction of MesoMT.
Pharmacologic GSK-3 $\beta$ Inhibition Blocks MesoMT

Because GSK-3 $\beta$ down-regulation markedly attenuated the induction of MT in HPMCs, the effect of GSK-3 $\beta$ inhibition was studied on the progression of MesoMT. For these studies GSK-3 $\beta$ was inhibited with the selective inhibitor 9ING41 in varying concentrations (10 to $0.5 \mu \mathrm{mol} / \mathrm{L}$ ) before the addition of TGF- $\beta$. Although all doses of 9ING41 attenuated the progression of MesoMT, only the higher doses of 9ING41 (10 to $1 \mu \mathrm{mol} / \mathrm{L})$ significantly blocked TGF- $\beta$-mediated induction of $\alpha$-SMA and Col-1 $(P<0.05)$ (Figure 4A). Further, TGF- $\beta$-mediated changes in cell structure were mitigated by GSK-3 $\beta$ inhibition (data not shown). In parallel qPCR studies, TGF$\beta$-mediated induction of Col-1 and $\alpha$-SMA were likewise blocked in 9ING41-treated cells (data not shown). Similar results were observed in HPMCs treated with plasmin (Figure 4B) and uPA (Figure 4C). An alternative GSK-3 $\beta$ inhibitor, 4-benzyl-2-methyl-1,2,4-thiadiazolidine-3,5-dione (TDZD-8) (Figure 4D), likewise blocked TGF- $\beta$-induced MesoMT. However, only the highest tested dose of TDZD$8(20 \mu \mathrm{mol} / \mathrm{L})$ was clearly effective.

Whether GSK-3 $\beta$ inhibition attenuated established MesoMT was next determined. Serum-starved HPMCs were treated with TGF- $\beta$ for 24 hours before the addition of 9ING41 (10 to $0.5 \mu \mathrm{mol} / \mathrm{L}$ ) and incubated for another 24 hours. Unlike the prevention studies described in the previous paragraph, only HPMCs treated with the highest concentration of 9ING41 (10 $\mu \mathrm{mol} / \mathrm{L})$ demonstrated less TGF- $\beta$-mediated increases in $\alpha$-SMA (Figure 5A). Conversely, Col-1 induction was dramatically reduced in the presence of all doses of the GSK-3 $\beta$ inhibitor. qPCR analyses, conducted in parallel, showed similar results (Figure 5B). These studies showed that GSK-3 $\beta$ inhibition with 9ING41 could block the progression and induction of MesoMT in stimulated HPMCs in vitro.

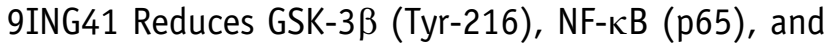
Smad2 Phosphorylation

Because Tyr-216 phosphorylation was increased in transitioning HPMCs and increased GSK-3 $\beta$ activity, the effect of 9ING41 was tested on the phosphorylation of GSK-3 $\beta$. HPMCs were treated with plasmin or UPA in the presence or absence of 9ING41 (10 $\mu \mathrm{mol} / \mathrm{L})$ for 15 minutes. 9ING41 reduced baseline Tyr-216 phosphorylation in serum-starved HPMCs (Figure 6A). Although uPA and plasmin increased Tyr-216 phosphorylation, 9ING41 treatment blocked this phosphorylation to levels below baselines observed in untreated cells, confirming that 9ING41 reduced GSK-3 $\beta$ activation in HPMCs.

GSK-3 $\beta$ was reported to modulate the activity of NF- $\kappa$ B. ${ }^{39-41}$ Further, it was previously shown that activation of the NF- $\kappa \mathrm{B}$ pathway was critical to progression of MesoMT. $^{38}$ To determine the effect of 9ING41 on NF- $\kappa$ B activation, 9ING41-treated HPMCs were immunoblotted for 


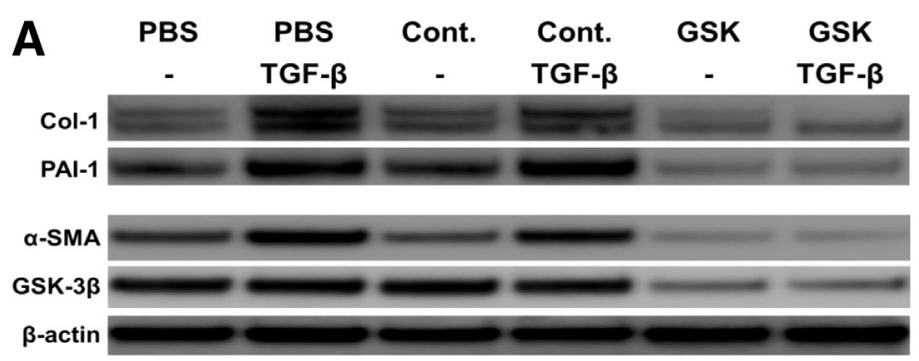

$\alpha$-SMA

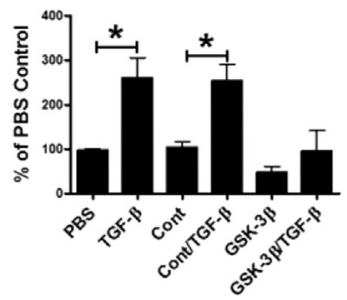

B

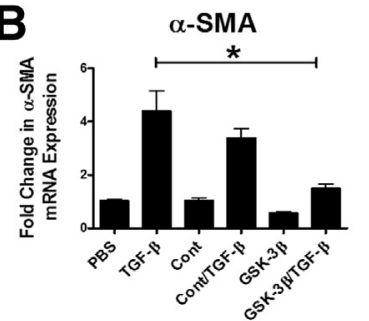

C

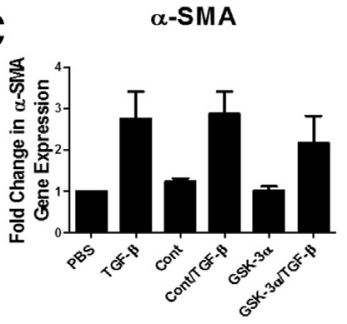

Col-1
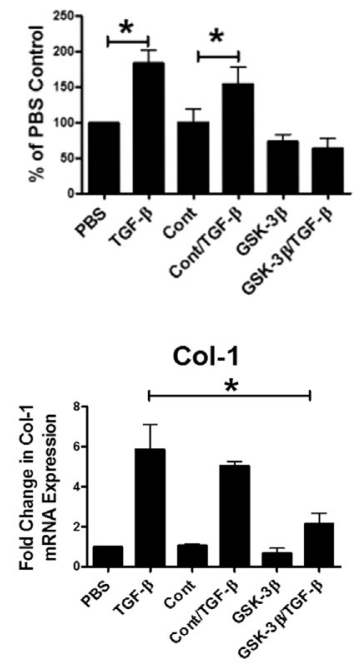

Col-1

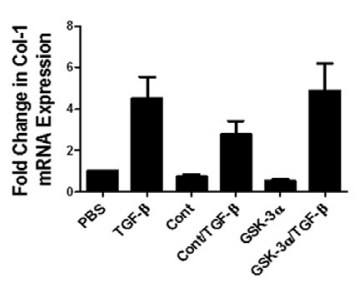

GSK-3 $\beta$

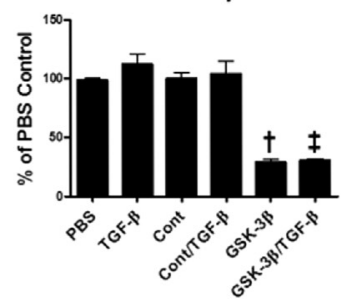

GSK-3 $\beta$

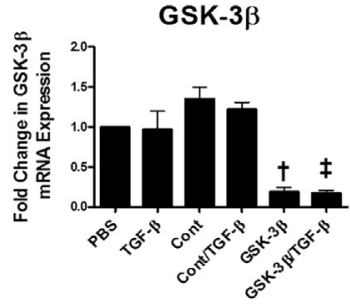

GSK-3 $\alpha$

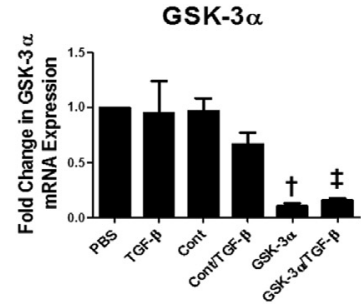

Figure 3 Glycogen synthase kinase (GSK)-3 $\beta$ down-regulation attenuates the induction of mesothelial mesenchymal transition (MesoMT). Untransfected, control siRNA, and GSK-3 $\beta$ siRNAtransfected cells were serum-starved for 24 hours. Cells were then treated with phosphate-buffered saline (PBS) or $5 \mathrm{ng} / \mathrm{mL}$ transforming growth factor (TGF)- $\beta$ for 48 hours. A: Conditioned media and cell lysates were resolved by SDS-PAGE and immunoblotted for collagen (Col)-1, plasminogen activator inhibitor (PAI)- $1, \alpha$-smooth muscle actin $(\alpha-S M A)$, and GSK-3 $\beta$ by Western blot analysis. $\beta$ Actin was used as loading control. B: Total RNA was isolated from untransfected, control siRNA-, and GSK- $3 \beta$ siRNA-transfected cells that had been treated with TGF- $\beta$ for 24 hours. Changes in $\alpha$ SMA, Col- 1 , and GSK-3 $\beta$ mRNA levels were determined by real-time quantitative PCR (qPCR) analyses. GAPDH was used as the reference gene. C: Total RNA was isolated from untransfected, control siRNA - and GSK- $3 \alpha$ siRNA-transfected cells that had been treated with TGF- $\beta$ for 24 hours. Changes in $\alpha$-SMA, Col- 1 , and GSK-3 $\alpha$ mRNA levels were determined by qPCR analyses. GAPDH was used as the reference gene. Data are expressed as means \pm SEM. $n=3$ independent experiments. ${ }^{*} P<0.05 ;{ }^{\dagger} P<0.05$ versus PBS control; ${ }^{\ddagger} P<0.05$ versus TGF- $\beta$ controls. Cont, control. phosphorylated $\mathrm{p} 65$, an indicator of $\mathrm{NF}-\kappa \mathrm{B}$ activity (Figure 6A). 9ING41 treatment reduced baseline p65 phosphorylation. Plasmin and uPA-mediated induction of p65 phosphorylation were likewise attenuated by 9ING41. These data showed that 9ING41 attenuated NF- $\kappa \mathrm{B}$ activation in HPMCs.

Because TGF- $\beta$-mediated MesoMT was due in part to Smad phosphorylation, ${ }^{14}$ the effect of 9ING41 on TGF$\beta$-mediated Smad2 phosphorylation was determined. As expected, TGF- $\beta$ robustly induced Smad 2 phosphorylation in HPMCs (Figure 6B). Conversely, 9ING41 treatment dramatically reduced Smad2 phosphorylation in TGF$\beta$-treated HPMCs (Figure 6B). The GSK-3 $\beta$ inhibitor did not induce apoptosis (cleaved caspase 3 ) or demonstrate other cytopathic effects at the doses used (data not shown). These findings demonstrated that GSK-3 $\beta$ inhibition by 9ING41 affected multiple signaling pathways in HPMCs undergoing MesoMT.
9ING41 Attenuates the Progression of EmpyemaMediated PF

Because GSK-3 $\beta$ inhibition blocked the progression of MT in HPMCs, the studies were extended to murine MPMCs in anticipation of in vivo interventions with 9ING41. MPMCs were treated with TGF- $\beta$ in the presence and absence of 10 $\mu \mathrm{mol} / \mathrm{L}$ 9ING41. Although TGF- $\beta$ induced $\alpha$-SMA expression in MPMCs, 9ING41 treatment effectively blocked $\alpha$-SMA induction (Figure 7A). This study showed that like HPMCs, MPMCs demonstrated similar responses to GSK-3 $\beta$ inhibition using 9ING41.

The effect of GSK-3 $\beta$ inhibition was next determined on the progression of pleural injury. For these studies mice were intrapleurally injected with $S$. pneumoniae to induce empyema, whereas control animals received intrapleural saline. The mice then remained untreated or were treated with 9ING41 or the vehicle control, dimethyl sulfoxide. 


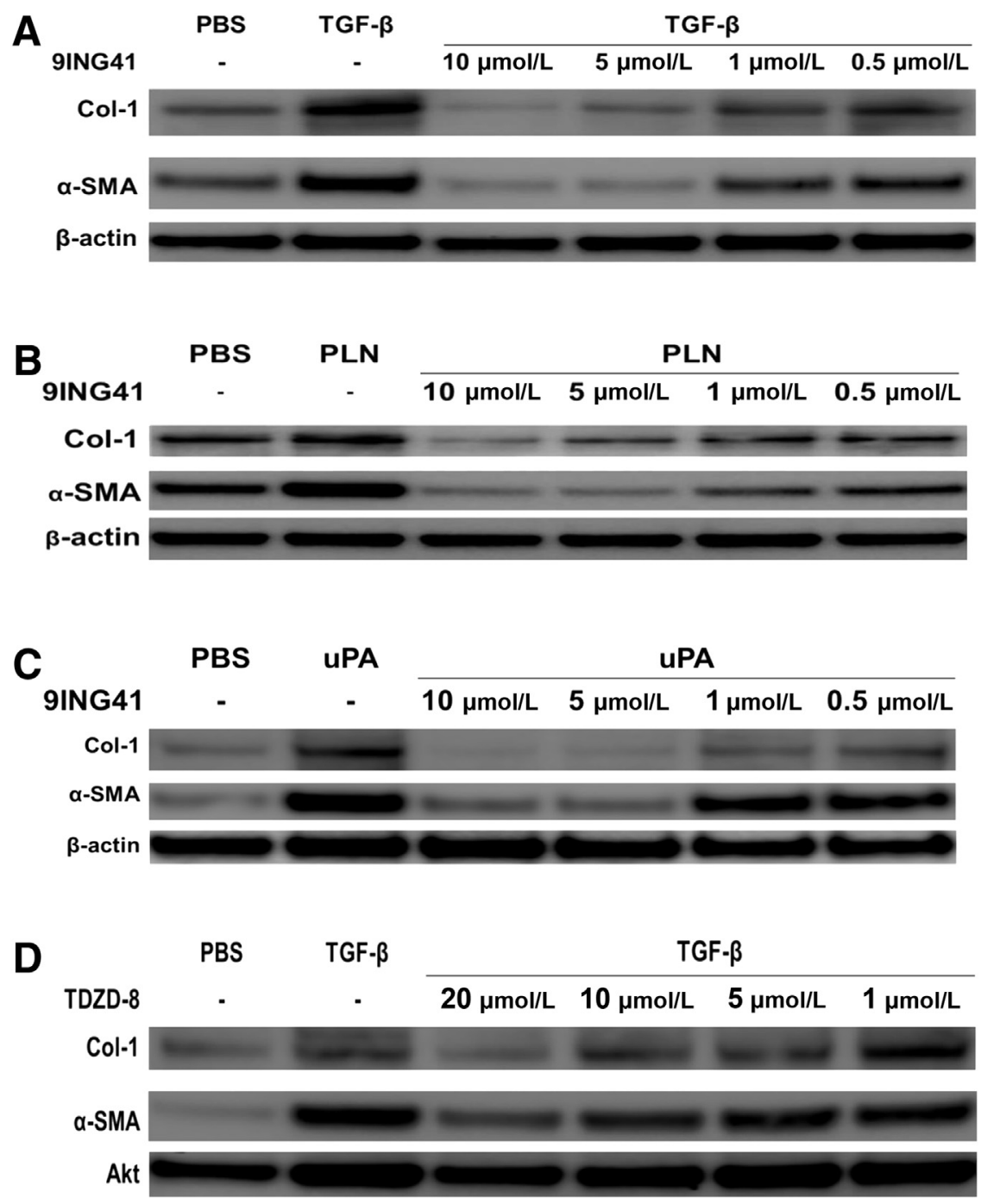

Figure 4 Glycogen synthase kinase (GSK)-3 $\beta$ inhibition with 9 ING41 blocks mesothelial mesenchymal transition (MesoMT) induction. A-C: Human primary mesenchymal cells (HPMCs) were treated with varying doses of 9ING41 (10 to 0.05 $\mu \mathrm{mol} / \mathrm{L})$ in serum-free media for 24 hours before the addition of $5 \mathrm{ng} / \mathrm{mL}$ transforming growth factor (TGF)- $\beta$ (A), $7 \mathrm{nmol} / \mathrm{L}$ plasmin (PLN) (B), or $20 \mathrm{nmol} / \mathrm{L}$ urokinase plasminogen activator (UPA) (C). Cells were then allowed to incubate for 48 hours. Conditioned media and lysates were then resolved by SDS-PAGE and immunoblotted for collagen (Col)- 1 and $\alpha$-smooth muscle actin ( $\alpha$ SMA) by Western blot analysis. $\beta$-Actin was used as loading control. D: HPMCs were treated with varying doses of 4-benzyl-2-methyl-1,2,4thiadiazolidine-3,5-dione (TDZD-8; 20 to $1 \mu \mathrm{mol} / \mathrm{L}$ ) in serum-free media for 24 hours before the addition of $5 \mathrm{ng} / \mathrm{mL}$ TGF- $\beta$. Conditioned media and lysates were then resolved by SDS-PAGE and immunoblotted for Col- 1 and $\alpha$-SMA by Western blot analysis. Akt was used as loading control. $n=2$ to 3 independent experiments. PBS, phosphatebuffered saline.

Lung volumes were markedly decreased in untreated and vehicle-treated mice with empyema compared with saline controls (Figure 7B). Further, pulmonary function testing showed untreated and vehicle-treated, injured mice with empyema demonstrated marked decrements of static lung compliance compared with saline-treated controls. 9ING41 treatment markedly improved lung volumes and compliance of $S$. pneumoniae-injured mice compared with untreated and vehicle-treated controls. Pulmonary function testing and lung volumes of mice without empyema but treated with 9ING41 were not notably different from uninjured saline controls (data not shown). GSK-3 $\beta$ inhibition with 9ING41 therefore attenuated restrictive outcomes after empyemamediated pleural injury.

\section{ING41 Treatment Reduces Pleural Thickening and Myofibroblast Accumulation}

Histologic and morphometric analyses were performed on the lung tissues collected from saline-treated control and
S. pneumoniae-injured mice that were untreated, treated with vehicle control, and treated with 9ING41. Trichromestained tissues were used to assess pleural thickness. All S. pneumonia-injured mice demonstrated notable increases in pleural thickness compared with saline controls (Figure 7C). Conversely, 9ING41 treatment notably reduced S. pneumoniae-mediated pleural thickening compared with untreated and vehicle-treated controls.

It was previously shown that pleural injury was associated with increasing numbers of myofibroblasts within the visceral pleural tissues. ${ }^{10,33}$ Lung tissues from $S$. pneumoniae-infected and control mice were next stained for $\alpha$-SMA, a myofibroblast biomarker, and calretinin, a mesothelial cell marker. Lung tissue from saline-treated mouse controls had no calretinin-positive cells exhibiting strong staining for $\alpha$-SMA within the pleural or subpleural regions. Although strong $\alpha$-SMA expression was detected in the pleura, cells expressing calretinin, of mice with S. pneumoniae-induced empyema, 9ING41-treated mice demonstrated reduced $\alpha$-SMA expression (Figure 7D). 

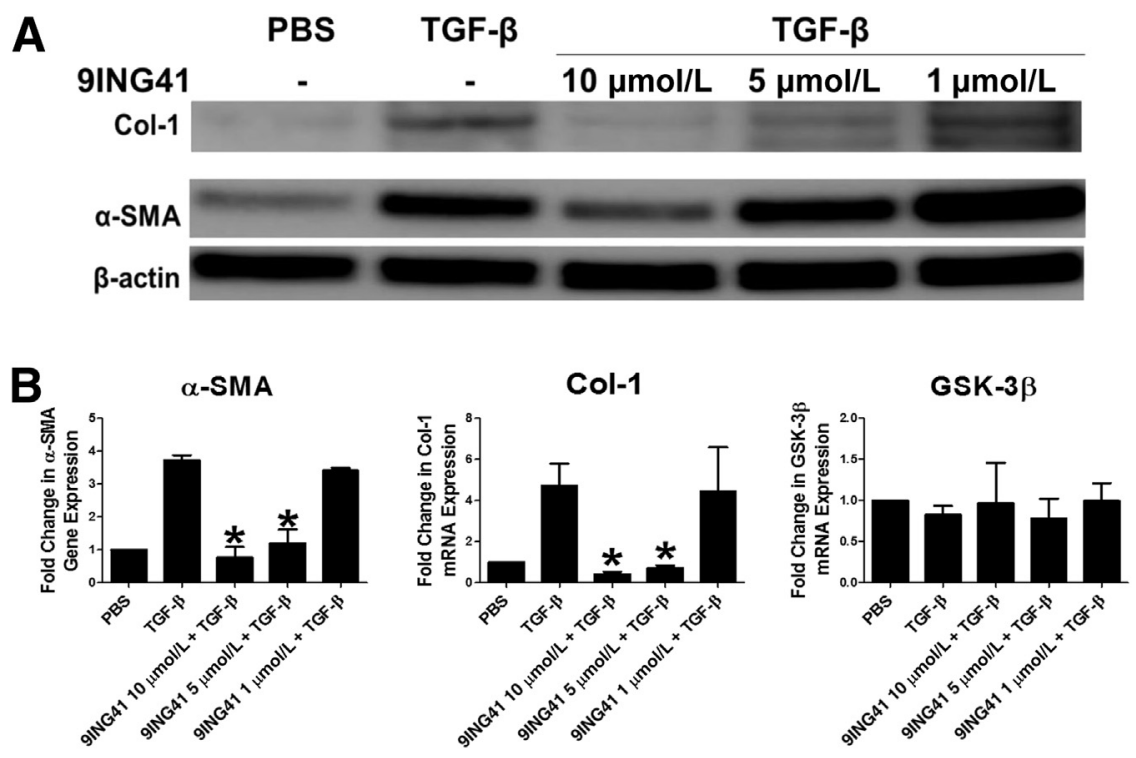

Figure 5 The glycogen synthase kinase (GSK)-3 $\beta$ inhibitor 9ING41 reverses established mesothelial mesenchymal transition (MesoMT). Serum-starved human primary mesenchymal cells (HPMCs) were treated with $5 \mathrm{ng} / \mathrm{mL}$ transforming growth factor (TGF)- $\beta$ for 24 hours. A: Varying doses of 9ING41 (10 to $0.5 \mu \mathrm{mol} / \mathrm{L})$ were then added to the TGF- $\beta$ treated cells and allowed to incubate for 48 hours. Conditioned media and lysates were resolved by SDSPAGE and immunoblotted for collagen (Col)-1 and $\alpha$-smooth muscle actin ( $\alpha$-SMA). $\beta$-Actin was used as loading control. B: For real-time quantitative PCR (qPCR) analyses varying doses of 9ING41 (10 to 0.5 $\mu \mathrm{g} / \mathrm{mL}$ ) were added to TGF- $\beta$-treated cells and then allowed to incubate for 24 hours. Total RNA was then isolated and transcribed into CDNA. $\alpha$-SMA and Col-1 expression was determined by GPCR analyses. GAPDH served as the reference gene. Data are expressed as means \pm SEM. $n=2$ to 3 independent experiments (A); $n=3$ independent experiments (B). ${ }^{*} P<0.05$ versus TGF- $\beta$ treatment. PBS, phosphate-buffered saline.
These data suggested that GSK-3 $\beta$ inhibition by 9 ING41 reduced myofibroblast accumulation and pleural thickening in vivo.

To confirm the effect of 9ING41 on GSK-3 $\beta$ activation, lung tissues were probed for GSK-3 $\beta$ Tyr-216 phosphorylation (Figure 7E). Tyr-216 phosphorylation was readily detectable in the pleural mesothelium of S. pneumoniaeinjured mice. Conversely, 9ING41-treated mice demonstrated less activated mesothelial GSK-3 $\beta$ than all other $S$. pneumoniae-injured groups. These data indicated that 9ING41 effectively inhibited GSK-3 $\beta$ activation in our empyema model.

\section{Discussion}

In this study two different yet intricately linked objectives were accomplished. First, it was shown that our previously published mouse model of $S$. pneumoniae-mediated empy$\mathrm{ema}^{33}$ is amenable to the testing of novel interventions designed to improve outcomes of organizing, infectious pleural injury. This model uses $S$. pneumoniae, a clinically relevant organism, to induce empyema and subsequently $\mathrm{PF}$. Second, a previously unrecognized, targetable participant in the progression of pleural injury, GSK-3 $\beta$, was identified. Although GSK-3 $\beta$ has been shown to be important in the
A

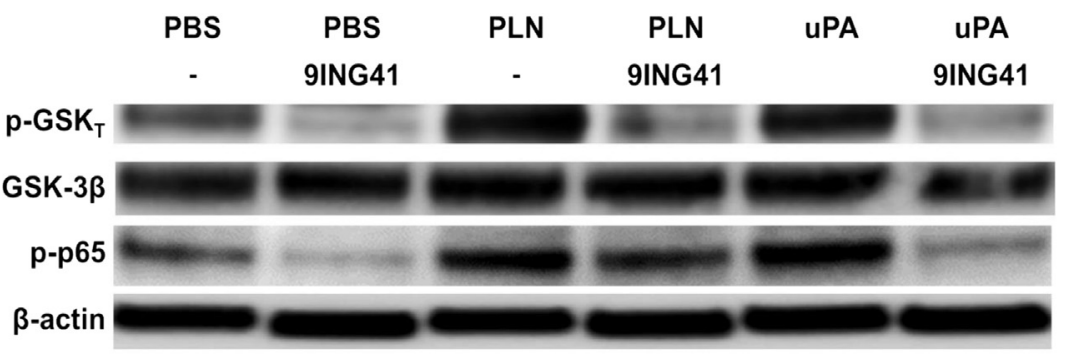

B PBS TGF- $\beta$ $10 \mu \mathrm{mol} / \mathrm{L}$ 9ING $5 \mu \mathrm{mol} / \mathrm{L}$ 9ING $1 \mu \mathrm{mol} / \mathrm{L}$ 9ING

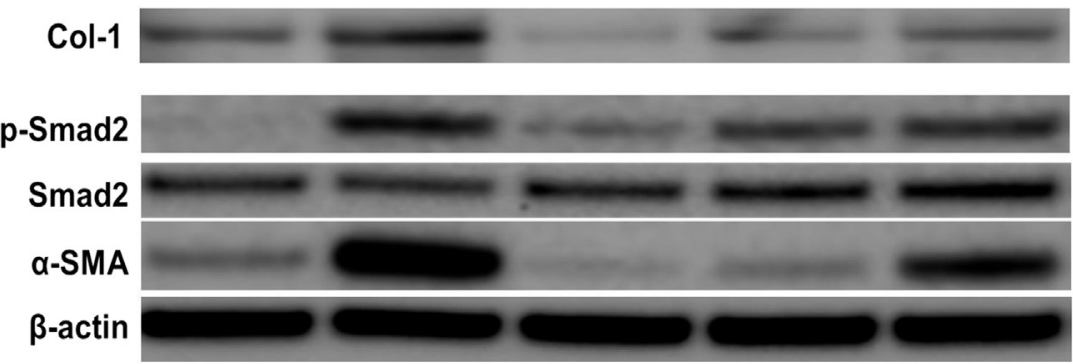

Figure 6 Glycogen synthase kinase (GSK)-3 $\beta$ inhibition by 9 ING41 reduces Tyr-216 phosphorylation of GSK-3 $\beta$ and phosphorylation of NF- $\kappa$ B and Smad2. A: Serum-starved human primary mesenchymal cells (HPMCs) were treated with phosphate-buffered saline (PBS), $7 \mathrm{nmol} / \mathrm{L}$ plasmin (PLN), and $20 \mathrm{nmol} / \mathrm{L}$ urokinase plasminogen activator (UPA) in the presence or absence of $10 \mu \mathrm{mol} / \mathrm{L}$ 9ING41. Cell lysates were then resolved by SDS-PAGE and immunoblotted for Tyr-216

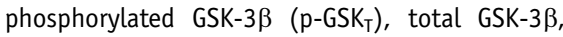
and phosphorylated p65 (p-p65). $\beta$-Actin was used as loading control. B: Serum-starved HPMCs were treated with PBS and $5 \mathrm{ng} / \mathrm{mL}$ transforming growth factor (TGF) $\beta$ in the presence and absence of 9ING41 (10 to $1 \mu \mathrm{mol} / \mathrm{L}$ ) for 48 hours. Conditioned media and cell lysates were then resolved by SDSPAGE and immunoblotted for collagen (Col)-1, phosphorylated Smad2 ( $p-S m a d 2)$, total Smad2, and $\alpha$-smooth muscle actin ( $\alpha$-SMA). $\beta$-Actin was used as loading control. $n=2$ independent experiments. 


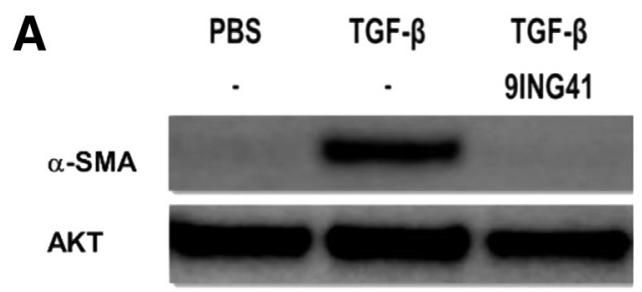

C

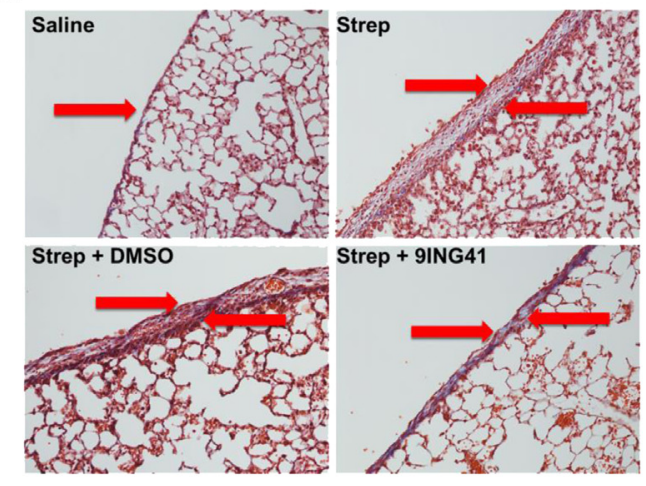

D

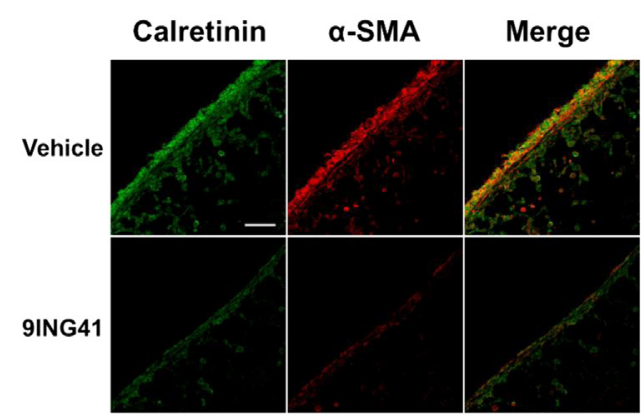

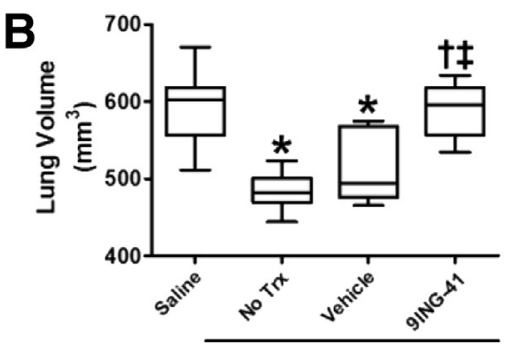

S. pneumoniae

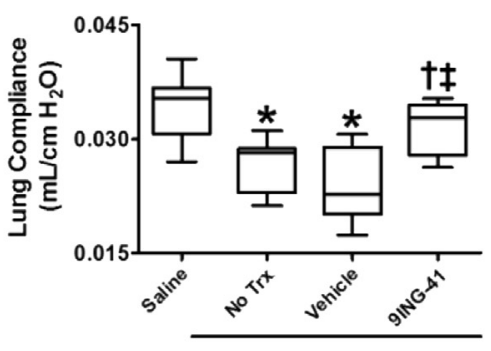

S. pneumoniae

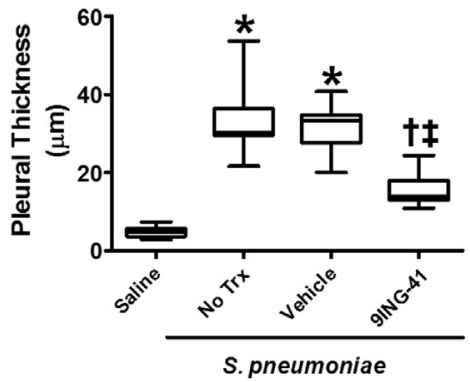

$\mathbf{E}$

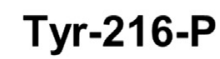

Vehicle

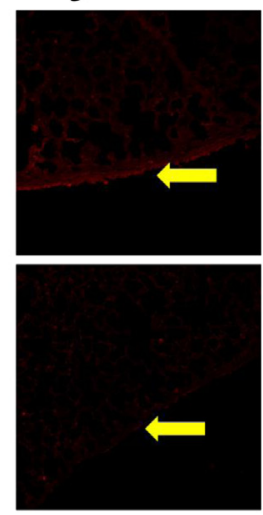

Figure 7 Streptococcus pneumoniae-mediated pleural injury is attenuated by treatment with 9ING41 A: Serum-starved murine primary mesenchymal cells (MPMCs) were treated with $5 \mathrm{ng} / \mathrm{mL}$ transforming growth factor (TGF)- $\beta$ in the presence or absence of $10 \mu \mathrm{mol} / \mathrm{L}$ 9ING41. Cell lysates were then resolved by SDS-PAGE and immunoblotted for $\alpha$-smooth muscle actin ( $\alpha$-SMA). Akt was used as loading control. B: $\mathrm{C57BL} / 6 \mathrm{~J}$ mice were intrapleurally injected with saline or S. pneumoniae $\left(1.8 \times 10^{8} \mathrm{cfu}\right)$. After 24 hours, mice were either left untreated or treated with dimethyl sulfoxide (vehicle) or $30 \mathrm{mg} / \mathrm{kg} 9 \mathrm{ING} 41 \mathrm{for} 6$ days. At the completion of the 7-day course, lung compliance was determined using the Scireq flexivent. Lung renditions were then collected by computed tomographic scan to determine lung volumes. C: Lung tissue sections from vehicle- and 9ING41-treated mice were Trichrome stained and images were taken. Pleural thicknesses were then measured and compared. Arrows indicate the mesothelium. D and E: Pleural sections from vehicle- and 9ING41-treated mice were immunostained for the mesothelial cell marker calretinin (green) and $\alpha$-SMA (red; D) or Tyr-216-phosphorylated glycogen synthase kinase (GSK)-3 $\beta$ (Tyr216-P) (E) and imaged by confocal microscopy. Arrows indicate the mesothelium. Colocalization of $\alpha$-SMA and calretinin is orange. Data are expressed as means \pm SEM. $n=2(\mathbf{A}) ; n=6$ to 10 mice per treatment $(\mathbf{B}) ; n=30$ fields per slide per mouse (C); $n=6$ to 10 animals per treatment (C); $n=30$ fields per mouse (D and $\mathbf{E}) ; n=3$ mice per treatment (D and $\mathbf{E}) .{ }^{*} P<0.05$ versus saline; ${ }^{\dagger} P<0.05$ versus no treatment; ${ }^{\ddagger} P<0.05$ versus vehicle. Scale bar $=50 \mu \mathrm{m}(\mathbf{C})$. Original magnification: $\times 20(\mathbf{C}) ; \times 40(\mathbf{D}$ and $\mathbf{E})$. Trx, treatment.

treatment of some cancers and the progression of fibrosis in other organs, its role in the pathogenesis of pleural injury has remained unclear until the present time. In peritoneal mesothelial cells, activation of GSK-3 $\beta$ protects against MesoMT $^{42-44}$ or promotes cell death, ${ }^{45}$ which is counter to our findings in this study. We posit that the disparate responses relate to the different origins of the cells, the antecedent environment in which the cells existed in vivo, or other factors related to their collection and maintenance. Our data clearly show that inhibition of GSK-3 $\beta$ improves physiological outcomes in the pleural compartment of mice with infectious pleural injury and that the effects are associated with inhibition of MesoMT and deposition of neomatrix. To our knowledge, this represents the first evidence along these lines and suggests that this approach merits further consideration for further translational investigation. 
GSK-3 $\beta$ expression was first shown to be enhanced in the pleural tissues of patients diagnosed with PF. Further, increased GSK-3 $\beta$ expression correlated with increased $\alpha$ SMA expression in the pleura of nonspecific pleuritis tissues. Although the specific cause(s) of the PF cases observed were not available, GSK-3 $\beta$ expression was consistently up-regulated in the pleural tissues of patients with a clinical diagnosis of nonspecific pleuritis compared with normal lung tissues. GSK-3 $\beta$ activity was measured in primary HPMCs. Although GSK-3 $\beta$ is a constitutively active kinase, its activity can be increased by localization to the nucleus and phosphorylation of Tyr-216. ${ }^{21,23}$ Phosphorylation of the Ser-9 residue of GSK-3 $\beta$ is reported to inhibit its activity. ${ }^{16,18,19}$ However, phosphorylated Ser-9 acts as a competitive inhibitor for the kinase active site and does not affect the intrinsic activity of the enzyme. Consequently, increased levels of primed substrate can overcome this inhibition. ${ }^{20}$ Further, Ser-9 phosphorylation has no effect on GSK-3 $\beta \beta^{\prime}$ s phosphorylation of unprimed substrates. These observations suggest that Tyr-216 phosphorylation may be a more accurate measure of GSK-3 $\beta$ activity. Plasmin and uPA, which induce and are otherwise locally expressed in pleural injuries involving MesoMT, ${ }^{10,33}$ mobilize GSK-3 $\beta$ to the nucleus and increase phosphorylation of Tyr-216. In addition, 9ING41 reduced NF- $\kappa B$ activation and Smad2 phosphorylation, suggesting that GSK-3 $\beta$ inhibition attenuates the progression of MesoMT by modulating these cell signaling pathways.

To determine the specific contribution of GSK-3 $\beta$ to the progression of MesoMT, GSK- $3 \alpha$ and $3 \beta$ were downregulated with siRNA. Although GSK-3 $\beta$ down-regulation markedly blocked the induction of MesoMT markers, GSK$3 \alpha$ down-regulation had no effect on their expression by HPMCs. These studies demonstrate the specific role of GSK-3 $\beta$ isoform in the progression of MesoMT. These findings were confirmed with two relatively specific GSK$3 \beta$ inhibitors 9ING41 and TDZD-8. 9ING41 was reported to inhibit GSK-3 $\beta$ activity through increased Ser-9 phosphorylation, similar to TDZD-8. ${ }^{32}$ However, our studies show that 9ING41 strongly reduced Tyr-216 phosphorylation. Further, 9ING41 effectively blocks MesoMT at lower concentrations than TDZD-8, suggesting the possibility that 9ING41 might be less prone to off-target effects and might be better tolerated. This difference is most likely a consequence of the increased efficacy of 9ING41 compared with alternative GSK-3 $\beta$ inhibitors. ${ }^{32}$ Further, 9ING41 treatment reduced p65 phosphorylation in plasmin- and uPA-treated HPMCs, indicative of decreased NF- $\mathrm{KB}$ activation. The findings suggest that the inhibitor mechanisms of TDZD-8 and 9ING41 may be distinctly different and suggest potential advantages for the use of 9ING41 to block GSK-3 $\beta$ in vivo.

Before in vivo studies, it was confirmed that 9ING41 could reverse establish MesoMT. MesoMT biomarkers can be detected 24 hours after treatment with TGF- $\beta .^{10,38}$ 9ING41 treatment reduced these biomarkers. Although
Western blot analysis showed only the highest dose of 9ING41 affected $\alpha$-SMA induction, qPCR analyses showed notable and consistent effects with lower 9ING41 doses. We posit that changes in RNA are more dynamic than changes in protein. These findings provided the rationale to conduct in vivo studies.

For in vivo analyses, a 9ING41 dose of $30 \mathrm{mg} / \mathrm{kg}$ was administered daily by intraperitoneal injection. Although higher doses have been reported in cancer studies and were well tolerated, ${ }^{32}$ this dose was chosen based on published lowest effective doses ${ }^{32}$ and personal communications with the manufacturer. 9ING41-treated mice tolerated these daily injections and demonstrated no adverse effects with respect to behavior, eating, drinking, or mobility. No notable differences in pulmonary functions and lung volumes were observed between the untreated and vehicle-treated $S$. pneumonia-injured groups. Our findings also show that dimethyl sulfoxide treatment did not worsen injury progression during the period of its delivery or by the development of subclinical lung or pleural injury. However, the lung volumes and pulmonary functions of the 9ING41treated mice were markedly improved compared with the other S. pneumonia-injured groups. Pleural thickening and $\alpha$-SMA expression in the pleural mesothelium were likewise reduced by GSK-3 $\beta$ inhibition, indicating that the improvements in imaging and physiological improvements were accompanied by the amelioration of MesoMT and reduction of the pleural rind and $\mathrm{PF}$ in the visceral pleural tissues of mice with $S$. pneumonia-induced empyema.

The effects of the administration of 9ING41 were also clearly associated with evidence that administration of the inhibitor locally blocked activation of GSK-3 $\beta$ in the mesothelium of mice with underlying empyema. Although Tyr-216 phosphorylation was strong within the visceral pleural mesothelium of $S$. pneumoniae-injured mice, this effect was reduced in 9ING41-treated mice compared with all other S. pneumoniae-injured groups. These observations show that the intrapleural 9ING41 doses administered effectively inhibited GSK-3 $\beta$ activation in the empyema model. GSK-3 $\beta$ inhibition improved lung function and PF induced by empyema in the model likely by reducing MesoMT with consequent reduction of pleural thickening. Although encouraging, the clinical applicability of these findings remains to be determined through toxicology analyses, dosing, and formulation optimization as well as additional pharmacokinetic and pharmacodynamic assessments that are beyond the scope of the present study.

\section{Conclusions}

This report provides evidence for the critical role that GSK$3 \beta$ plays in the progression of MesoMT, pleural rind formation, and restrictive consequences of excessive pleural organization that occurs with $S$. pneumoniae-induced empyema in mice. Components of the fibrinolytic pathway, 
including plasmin and uPA, are expressed in the setting of pleural inflammation and repair and may predispose to the development of PF by activation of GSK-3 $\beta$ and MesoMT. TGF- $\beta$ is likewise locally expressed and implicated in the pathogenesis of MesoMT, ${ }^{10-12}$ pleural rind formation, and $\mathrm{PF}$, and it is now demonstrated that it too can activate GSK$3 \beta$ during induction of MesoMT in PMCs. It is highly likely that diverse alternative factors that drive MT in other cell types ${ }^{10,13,29,33,38}$ may likewise activate GSK-3 $\beta$ in vivo and thereby promote PF. Although down-regulation or inhibition of GSK-3 $\beta$ can attenuate the induction of MesoMT in vitro, our findings show that pharmacologic blockade of GSK-3 $\beta$ in vivo is feasible, well tolerated, and salutary. Therapeutic targeting of GSK-3 $\beta$ activity improved lung function and mitigated pleural rind formation in our empyema model. Our findings provide a strong rationale for the continued investigation of GSK-3 $\beta$ as a candidate target for organizing pleural injury/PF.

\section{Acknowledgments}

J.B., G.S., A.F., A.J., S.O., W.Q., K.B.K., Y.T., S.K., and T.A.T. performed experiments; M.I., S.I., and T.A.T. designed experiments and prepared and approved the manuscript.

\section{References}

1. Huggins JT, Sahn SA: Causes and management of pleural fibrosis. Respirology 2004, 9:441-447

2. Lee YC, Vaz MA, Ely KA, McDonald EC, Thompson PJ, Nesbitt JC, Light RW: Symptomatic persistent post-coronary artery bypass graft pleural effusions requiring operative treatment: clinical and histologic features. Chest 2001, 119:795-800

3. Jantz MA, Antony VB: Pleural fibrosis. Clin Chest Med 2006, 27: $181-191$

4. Heffner JE, Klein JS, Hampson C: Interventional management of pleural infections. Chest 2009, 136:1148-1159

5. Colice GL, Idell S: Response. Chest 2014, 146:e104-e105

6. Colice GL, Idell S: Rebuttal from Drs Colice and Idell. Chest 2014, $145: 21-23$

7. Colice GL, Idell S: Counterpoint: should fibrinolytics be routinely administered intrapleurally for management of a complicated parapneumonic effusion? No. Chest 2014, 145:17-20

8. Girdhar A, Shujaat A, Bajwa A: Management of infectious processes of the pleural space: a review. Pulm Med 2012, 2012:816502

9. Abu-Daff S, Maziak DE, Alshehab D, Threader J, Ivanovic J, Deslaurier V, Villeneuve PJ, Gilbert S, Sundaresan S, Shamji F, Lougheed C, Seely JM, Seely AJ: Intrapleural fibrinolytic therapy (IPFT) in loculated pleural effusions-analysis of predictors for failure of therapy and bleeding: a cohort study. BMJ Open 2013, 3:e001887

10. Tucker TA, Jeffers A, Alvarez A, Owens S, Koenig K, Quaid B, Komissarov AA, Florova G, Kothari H, Pendurthi U, Mohan Rao LV, Idell S: Plasminogen activator inhibitor-1 deficiency augments visceral mesothelial organization, intrapleural coagulation, and lung restriction in mice with carbon black/bleomycin-induced pleural injury. Am J Respir Cell Mol Biol 2014, 50:316-327

11. Decologne N, Wettstein G, Kolb M, Margetts P, Garrido C, Camus P, Bonniaud P: Bleomycin induces pleural and subpleural fibrosis in the presence of carbon particles. Eur Respir J 2010, 35:176-185
12. Decologne N, Kolb M, Margetts PJ, Menetrier F, Artur Y, Garrido C, Gauldie J, Camus P, Bonniaud P: TGF-betal induces progressive pleural scarring and subpleural fibrosis. J Immunol 2007, 179: 6043-6051

13. Kalluri R, Neilson EG: Epithelial-mesenchymal transition and its implications for fibrosis. J Clin Invest 2003, 112:1776-1784

14. Nasreen N, Mohammed KA, Mubarak KK, Baz MA, Akindipe OA, Fernandez-Bussy S, Antony VB: Pleural mesothelial cell transformation into myofibroblasts and haptotactic migration in response to TGF-beta1 in vitro. Am J Physiol Lung Cell Mol Physiol 2009, 297: L115-L124

15. Idell S: The pathogenesis of pleural space loculation and fibrosis. Curr Opin Pulm Med 2008, 14:310-315

16. Woodgett JR: Molecular cloning and expression of glycogen synthase kinase-3/factor A. EMBO J 1990, 9:2431-2438

17. Cortes-Vieyra R, Bravo-Patino A, Valdez-Alarcon JJ, Juarez MC, Finlay BB, Baizabal-Aguirre VM: Role of glycogen synthase kinase-3 beta in the inflammatory response caused by bacterial pathogens. J Inflamm (Lond) 2012, 9:23

18. Doble BW, Woodgett JR: GSK-3: tricks of the trade for a multi-tasking kinase. J Cell Sci 2003, 116:1175-1186

19. Hughes K, Nikolakaki E, Plyte SE, Totty NF, Woodgett JR: Modulation of the glycogen synthase kinase-3 family by tyrosine phosphorylation. EMBO J 1993, 12:803-808

20. Frame S, Cohen P, Biondi RM: A common phosphate binding site explains the unique substrate specificity of GSK3 and its inactivation by phosphorylation. Mol Cell 2001, 7:1321-1327

21. Meares GP, Jope RS: Resolution of the nuclear localization mechanism of glycogen synthase kinase-3: functional effects in apoptosis. J Biol Chem 2007, 282:16989-17001

22. Jope RS, Johnson GV: The glamour and gloom of glycogen synthase kinase-3. Trends Biochem Sci 2004, 29:95-102

23. Bijur GN, Jope RS: Glycogen synthase kinase-3 beta is highly activated in nuclei and mitochondria. Neuroreport 2003, 14:2415-2419

24. Eldar-Finkelman H: Glycogen synthase kinase 3: an emerging therapeutic target. Trends Mol Med 2002, 8:126-132

25. Bilim V, Ougolkov A, Yuuki K, Naito S, Kawazoe H, Muto A, Oya M, Billadeau D, Motoyama T, Tomita Y: Glycogen synthase kinase-3: a new therapeutic target in renal cell carcinoma. Br J Cancer 2009, 101:2005-2014

26. Ougolkov AV, Billadeau DD: Inhibition of glycogen synthase kinase3. Methods Mol Biol 2008, 468:67-75

27. Ougolkov AV, Bone ND, Fernandez-Zapico ME, Kay NE, Billadeau DD: Inhibition of glycogen synthase kinase-3 activity leads to epigenetic silencing of nuclear factor kappaB target genes and induction of apoptosis in chronic lymphocytic leukemia B cells. Blood 2007, 110:735-742

28. Shyu HY, Ko CJ, Luo YC, Lin HY, Wu SR, Lan SW, Cheng TS, Hu SH, Lee MS: Ketamine increases permeability and alters epithelial phenotype of renal distal tubular cells via a GSK-3beta-dependent mechanism. J Cell Biochem 2016, 117:881-893

29. Lan A, Qi Y, Du J: Akt2 mediates TGF-beta1-induced epithelial to mesenchymal transition by deactivating GSK3beta/snail signaling pathway in renal tubular epithelial cells. Cell Physiol Biochem 2014, 34:368-382

30. Singh SP, Tao S, Fields TA, Webb S, Harris RC, Rao R: Glycogen synthase kinase-3 inhibition attenuates fibroblast activation and development of fibrosis following renal ischemia-reperfusion in mice. Dis Model Mech 2015, 8:931-940

31. Cuzzocrea S, Crisafulli C, Mazzon E, Esposito E, Muia C, Abdelrahman M, Di Paola R, Thiemermann C: Inhibition of glycogen synthase kinase-3beta attenuates the development of carrageenaninduced lung injury in mice. Br J Pharmacol 2006, 149:687-702

32. Hilliard TS, Gaisina IN, Muehlbauer AG, Gaisin AM, Gallier F, Burdette JE: Glycogen synthase kinase 3beta inhibitors induce apoptosis in ovarian cancer cells and inhibit in-vivo tumor growth. Anticancer Drugs 2011, 22:978-985 
33. Tucker TA, Jeffers A, Boren J, Quaid B, Owens S, Koenig KB, Tsukasaki Y, Florova G, Komissarov AA, Ikebe M, Idell S: Organizing empyema induced in mice by Streptococcus pneumoniae: effects of plasminogen activator inhibitor-1 deficiency. Clin Transl Med 2016, 5:17

34. Williams L, Tucker TA, Koenig K, Allen T, Rao LV, Pendurthi U, Idell S: Tissue factor pathway inhibitor attenuates the progression of malignant pleural mesothelioma in nude mice. Am J Respir Cell Mol Biol 2012, 46:173-179

35. Tucker TA, Williams L, Koenig K, Kothari H, Komissarov AA, Florova G, Mazar AP, Allen TC, Bdeir K, Mohan Rao LV, Idell S: Lipoprotein receptor-related protein 1 regulates collagen 1 expression, proteolysis, and migration in human pleural mesothelial cells. Am J Respir Cell Mol Biol 2012, 46:196-206

36. Idell S, Zwieb C, Kumar A, Koenig KB, Johnson AR: Pathways of fibrin turnover of human pleural mesothelial cells in vitro. Am J Respir Cell Mol Biol 1992, 7:414-426

37. Jeffers A, Owens S, Koenig K, Quaid B, Pendurthi UR, Rao VM, Idell S, Tucker TA: Thrombin down-regulates tissue factor pathway inhibitor expression in a PI3K/nuclear factor-kappaB-dependent manner in human pleural mesothelial cells. Am J Respir Cell Mol Biol 2015, 52:674-682

38. Owens S, Jeffers A, Boren J, Tsukasaki Y, Koenig K, Ikebe M, Idell S, Tucker TA: Mesomesenchymal transition of pleural mesothelial cells is PI3K and NF-kappaB dependent. Am J Physiol Lung Cell Mol Physiol 2015, 308:L1265-L1273
39. Schwabe RF, Brenner DA: Role of glycogen synthase kinase-3 in TNF-alpha-induced NF-kappaB activation and apoptosis in hepatocytes. Am J Physiol Gastrointest Liver Physiol 2002, 283:G204-G211

40. Chen H, Yang S, Yang Z, Ma L, Jiang D, Mao J, Jiao B, Cai Z: Inhibition of GSK-3beta decreases NF-kappaB-dependent gene expression and impairs the rat liver regeneration. J Cell Biochem 2007, 102: $1281-1289$

41. Hoeflich KP, Luo J, Rubie EA, Tsao MS, Jin O, Woodgett JR: Requirement for glycogen synthase kinase-3beta in cell survival and NF-kappaB activation. Nature 2000, 406:86-90

42. Fan M, Liu F, Yang Y, Ye Y, Huang G: [Phosphorylation of glycogen synthase kinase-3beta induces epithelial mesenchymal transition in human peritoneal mesothelial cells] Chinese. Zhong Nan Da Xue Xue Bao Yi Xue Ban 2010, 35:329-334

43. Jang YH, Shin HS, Sun Choi H, Ryu ES, Jin Kim M, Ki Min S, Lee JH, Kook Lee H, Kim KH, Kang DH: Effects of dexamethasone on the TGF-beta1-induced epithelial-to-mesenchymal transition in human peritoneal mesothelial cells. Lab Invest 2013, 93:194-206

44. Luo L, Liu H, Dong Z, Sun L, Peng Y, Liu F: Small interfering RNA targeting ILK inhibits EMT in human peritoneal mesothelial cells through phosphorylation of GSK3beta. Mol Med Rep 2014, 10: $137-144$

45. Rusai K, Herzog R, Kuster L, Kratochwill K, Aufricht C: GSK-3beta inhibition protects mesothelial cells during experimental peritoneal dialysis through upregulation of the heat shock response. Cell Stress Chaperones 2013, 18:569-579 